\title{
Detection of epidermal growth factor receptor mutations in lung adenocarcinoma cytological specimens by immunocytochemistry
}

\author{
MASAMI YOSHIDA, TADASUKE NAGATOMO, TAKAFUMI OHNISHI, \\ MAYUMI KAWASHIMA, AKIRA NAITOH and EIICHI MORII
}

\author{
Department of Pathology, Osaka University Graduate School of Medicine, Suita, Osaka 565-0871, Japan
}

Received May 18, 2017; Accepted August 16, 2017

DOI: $10.3892 / \mathrm{mco} .2017 .1451$

\begin{abstract}
Tyrosine kinase inhibitors of epidermal growth factor receptor (EGFR) improve the survival of patients with lung adenocarcinoma, and determine the EGFR mutation status before treatment is necessary. In contrast to biopsy samples, cytological specimens are obtained less invasively and are useful for EGFR mutation analyses. Recently, novel antibodies against two major EGFR mutations were developed: SP111, which is specific for the E746-A750 deletion in exon 19; and SP125, which is specific for the L858R mutation. To the best of our knowledge, no study has evaluated cytological specimens using the two novel antibodies, thus their specificity and sensitivity were examined in surgical resection, and cytological lung adenocarcinoma samples in the present study. Previous screening for EGFR mutation status by molecular testing identified delE746-A750 in 3 cases and the L858R mutation in 7 cases; the other cases did not have the L858R or the delE746-A750 mutation. Using a four-grade scoring system (score 0 to $3+$ ), the immunohistochemistry (IHC) and immunocytochemistry (ICC) results were compared with those of molecular testing. Using a score of $\geq 2$ as positive, IHC and ICC using SP111 demonstrated sensitivities of 100 and $33.3 \%$, and specificities of 100 and $100 \%$, respectively. IHC and ICC using SP125 revealed sensitivities of 100 and $71.4 \%$, and specificities of 100 and $100 \%$, respectively. Therefore, screening for EGFR mutations by ICC may facilitate therapeutic decision-making, particularly in medical centers that are unable to perform molecular testing.
\end{abstract}

\section{Introduction}

Lung cancer is the leading cause of cancer-related mortality and is responsible for approximately 1.59 million deaths

Correspondence to: Dr Eiichi Morii, Department of Pathology, Osaka University Graduate School of Medicine, 2-2 Yamadaoka, Suita, Osaka 565-0871, Japan

E-mail: morii@molpath.med.osaka-u.ac.jp

Key words: epidermal growth factor receptor, mutation-specific antibody, immunohistochemistry, immunocytochemistry, lung adenocarcinoma annually worldwide (1). Non-small cell lung carcinoma (NSCLC) accounts for more than $80 \%$ of lung cancer cases, with adenocarcinoma (ADC) being the most common histological subtype. Detection of activating somatic mutations in the epidermal growth factor receptor $(E G F R)$ gene in ADC (2-5) has revolutionized diagnosis and treatment and resulted in a shift towards individual targeted therapy (2). Although several mutations can occur in exons 18-21 of the tyrosine kinase domain of EGFR, approximately $90 \%$ are the 15 bp (E746-750) in-frame deletion in exon 19 or the L858R point mutation in exon $21(3,4,6)$. Mutational status is associated with a clinical response to EGFR-tyrosine kinase inhibitor (TKI) treatment (2-7). EGFR-TKIs are more efficacious than carboplatin-paclitaxel as an initial treatment (8).

Direct DNA sequencing is the classical method used to detect EGFR mutations; however, this method requires a sufficient quantity of DNA. In addition, the high costs of equipment and reagents, and the time-consuming procedure, hamper its application in clinical practice. To overcome these issues, various molecular tests for EGFR mutations have been developed, such as the Scorpion amplified refractory mutation system and polymerase chain reaction single-strand conformation polymorphism $(9,10)$. However, many patients in developing countries do not undergo molecular testing due to the lack of available equipment and trained personnel. Immunohistochemistry (IHC) is an inexpensive and accurate method of identifying EGFR mutations and is available in most pathology laboratories. Antibodies specific for the exon 19 deletion E746-A750 (delE746-A750) and the L858R mutation have been developed to assess tumor EGFR status (11-20). A meta-analysis recommended that IHC but not molecular testing is suitable for detection of EGFR mutations (21).

As approximately $70 \%$ of NSCLC patients are diagnosed at an advanced stage and are thus ineligible for surgical resection $(22,23)$, therapeutic decision-making is dependent on the availability of biopsy samples or cytology specimens. Compared with biopsy samples, obtaining cytological specimens is minimally invasive and simple. Several studies have evaluated cytological specimens using immunocytochemistry (ICC) with EGFR mutation-specific antibodies (18,24-26); however, the results were inconsistent (sensitivity $43-100 \%$ and specificity $74-100 \%)(18,24-26)$. Two novel antibodies against EGFR-mutated proteins were developed recently. SP111 is specific for delE746-A750 and SP125 for the L858R mutation; 
both SP111 and SP125 show an efficacy similar to that of the original clone (27-29). To date, no study has assessed the utility of SP111 or SP125 for cytological specimens. Here, we examined the specificity and sensitivity of IHC and ICC using the SP111 and SP125 antibodies in surgical and cytological samples from patients with lung adenocarcinoma.

\section{Patients and methods}

Clinical samples and DNA analysis. This study involved 17 patients with pulmonary adenocarcinoma from whom surgical and cytological samples were obtained from January 2015 to March 2017 at Osaka University Medical Hospital. Formalin-fixed paraffin-embedded (FFPE) tissue sections $(5 \mu \mathrm{m})$ were prepared. DNA extraction from FFPE samples was performed according to the standard procedure of the Cobas DNA Sample Preparation kit (Roche Molecular Systems, Inc. Alameda, CA, USA). Briefly, the samples were incubated with a protease in chaotropic lysis/binding buffer to release nucleic acids and protect genomic DNA from degradation by DNase. The amount of genomic DNA was spectrophotometrically determined (Nanodrop ND-1000, Thermo Scientific, Wilmington, DE, USA) and adjusted to $2 \mathrm{ng} / \mu \mathrm{l}$. DNA (150 ng) was obtained for the Cobas EGFR assay. Target DNA was amplified and detected using the Cobas 4800 Analyzer (Roche Molecular Systems, Inc.) according to the manufacturer's instructions.

The study protocol was approved by the Research Ethics Board of the Osaka University Research Committee and conducted according to Institutional Review Board guidelines (cat. no. 16293).

IHC and ICC of EGFR mutations. FFPE tissue sections (5 $\mu \mathrm{m})$ were stained immunohistochemically using the SP111 anti-EGFR delE746-A750 rabbit monoclonal antibody and SP125 anti-EGFR L858R rabbit monoclonal antibody (Ventana Medical Systems, Tucson, AZ, USA) and an automatic staining system (Ventana BenchMark XT; Ventana Medical Systems). Briefly, the sections were incubated with SP111 or SP125 for $16 \mathrm{~min}$ at $37^{\circ} \mathrm{C}$, and immunoreactions were detected using the Ultraview Universal DAB detection kit. The negative control lacked a primary antibody. The slides were assessed by at least two pathologists blinded to the EGFR mutation status. The IHC staining was scored based on the staining intensity and percentage staining area in the membrane and/or cytoplasm of tumor cells, as follows (18): 0 no staining; 1+, light-yellow staining with no obvious particulates or yellow staining with obvious particulates in $<10 \%$ of tumor cells; $2+$, yellow staining with obvious particulates in $>10 \%$ of tumor cells or brown staining with obvious particulates in $<10 \%$ of tumor cells; and $3+$, brown staining with obvious particulates in $>10 \%$ of tumor cells. Scores of $2+$ and $3+$ were considered positive (18).

A cell-transfer technique was used for ICC. A layer of Malinol medium (Muto Pure Chemicals Co. Ltd., Tokyo, Japan) was spread uniformly over the top of the cellular material. The slide was placed into a $70^{\circ} \mathrm{C}$ oven for $72 \mathrm{~h}$ to harden the coating material and then transferred to a water bath at $50^{\circ} \mathrm{C}$ for 15 min to soften the Malinol medium. Using a blade, the liquid coverslip and attached cells were slowly peeled off the slide. The peeled membrane was sectioned into 3-5 pieces. Each section was transferred to another slide, on which ICC was performed using a similar method to that of IHC. Staining was evaluated as for IHC (18).

Statistical analysis . Statistical analyses were performed using R version 3.2.2 (https://cran.r-project.org/bin/windows/base/). Antibody performance was assessed by determining the sensitivity, specificity, positive predictive value (PPV), and negative predictive value (NPV). The agreement between IHC or ICC and molecular testing was calculated using Cohen's kappa score. A $\kappa$ value of 0.81-1.0 was defined as nearly perfect agreement, $0.61-0.8$ as substantial agreement, $0.41-0.60$ as moderate agreement, 0.21 to 0.40 as fair agreement, and 0.00-0.20 as slight agreement.

\section{Results}

Patient characteristics. Of the 192 patients with pulmonary adenocarcinoma who underwent surgical resection from January 2015 to March 2017 at Osaka University Medical Hospital, cytological specimens were obtained from 17 patients. The clinicopathological characteristics of the patients are shown in Table I. The cytologic specimens comprised exfoliative (bronchial brush/wash/lavage) $(n=9)$, transbronchial fine-needle aspiration (FNA; $n=7$ ), and transthoracic FNA $(n=1)$ specimens. The age of the patients was 53-77 years (median, 67.2 years). Twelve and five of the patients were male and female, respectively. Six cases were stage IA, seven stage IB, two stage IIA, and two stage IIIA. All the cases had previously undergone screening for EGFR mutations by molecular testing. Exon 19 deletion (delE746-A750) was present in three patients and the L858R mutation in exon 21 in seven patients; the other patients had neither the L858R mutation nor delE746-A750 (Table I).

IHC using SP111 and SP125. IHC using SP111 and SP125 yielded scores of 0 to 3+ (Figs. 1 and 2). Using SP111, 13 of 17 cases showed a score of 0 , one a score of $1+$, one a score of $2+$, and two a score of 3+ (Table I). Using SP125, 7 of 17 cases showed a score of 0 , three a score of $1+$, four a score of $2+$, and three a score of $3+$ (Table I). The three and seven cases with a score of 2+ or 3+ using SP111 and SP125, respectively, were evaluated as SP111- and SP125-positive, respectively, as described previously (18) (Table II).

ICC using SP111 and SP125. ICC using SP111 and SP125 yielded four scores (Figs. 3A-C and 4A-D). Using SP111, 13 of 17 cases showed a score of 0 , three a score of $1+$, and one a score of $2+$. Using SP125, 6 of 17 cases showed a score of 0 , six a score of $1+$, two a score of $2+$, and three a score of $3+$. The one case with a score of 2+ using SP111 and the five cases with a score of $2+$ or $3+$ using SP125 were evaluated as SP111- and SP125-positive, respectively (Table III).

EGFR mutations. The seven cases without EGFR mutations were negative by IHC using SP111 and SP125. The three cases with delE746-A750 were positive using SP111 and negative using SP125. Similarly, the seven cases with the L858R mutation were positive using SP125 and negative using SP111. 
Table I. Patient characteristics and EGFR mutations status in primary NSCLC samples and comparative analysis of IHC and ICC.

\begin{tabular}{|c|c|c|c|c|c|c|c|c|c|}
\hline \multirow[b]{2}{*}{ Patient no. } & \multirow{2}{*}{$\begin{array}{l}\text { Age, } \\
\text { years }\end{array}$} & \multirow[b]{2}{*}{ Sex } & \multirow[b]{2}{*}{ Stage } & \multirow[b]{2}{*}{ EGFR mutation status } & \multicolumn{2}{|c|}{$\mathrm{IHC}$} & \multicolumn{2}{|c|}{$\mathrm{ICC}$} & \multirow[b]{2}{*}{ SP125 } \\
\hline & & & & & SP111 & SP125 & Sample type & SP111 & \\
\hline 1 & 60 & $\mathrm{~F}$ & IB & L858R & 0 & $3+$ & $\mathrm{BB}$ & 0 & $3+$ \\
\hline 2 & 77 & M & IB & L858R & 0 & $2+$ & FNA & 0 & $1+$ \\
\hline 3 & 53 & $\mathrm{~F}$ & IIA & L858R & 0 & $2+$ & FNA & 0 & $3+$ \\
\hline 4 & 71 & M & IIA & L858R & 0 & $3+$ & $\mathrm{BB}$ & $1+$ & $3+$ \\
\hline 5 & 59 & $\mathrm{~F}$ & IA & L858R & 0 & $2+$ & FNA & 0 & $2+$ \\
\hline 6 & 76 & M & IA & L858R & 0 & $2+$ & FNA & 0 & $1+$ \\
\hline 7 & 61 & M & IB & L858R & 0 & $3+$ & FNA & $1+$ & $2+$ \\
\hline 8 & 72 & M & IA & Exon 19 del & $2+$ & 0 & $\mathrm{BB}$ & 0 & 0 \\
\hline 9 & 70 & $\mathrm{~F}$ & IA & Exon 19 del & $3+$ & $1+$ & FNA & 0 & 0 \\
\hline 10 & 76 & M & IB & Exon 19 del & $3+$ & 0 & FNA & $2+$ & 0 \\
\hline 11 & 69 & M & IIIA & No mutation & 0 & 0 & $\mathrm{BB}$ & 0 & 0 \\
\hline 12 & 72 & M & IIIA & No mutation & 0 & 0 & $\mathrm{BB}$ & 0 & 0 \\
\hline 13 & 77 & M & IB & No mutation & 0 & 0 & FNA & $1+$ & $1+$ \\
\hline 14 & 67 & M & IA & No mutation & $1+$ & 0 & $\mathrm{BB}$ & 0 & 0 \\
\hline 15 & 53 & M & IB & No mutation & 0 & 0 & $\mathrm{BB}$ & 0 & $1+$ \\
\hline 16 & 54 & $\mathrm{~F}$ & IA & No mutation & 0 & $1+$ & $\mathrm{BB}$ & 0 & $1+$ \\
\hline 17 & 75 & M & IB & No mutation & 0 & $1+$ & $\mathrm{BB}$ & 0 & $1+$ \\
\hline
\end{tabular}

BB, bronchial brush; FNA, fine-needle aspiration; M, male; F, female; EGFR, epidermal growth factor receptor; IHC, immunohistochemistry; ICC, immunocytochemistry; NSCLC, non-small cell lung carcinoma.
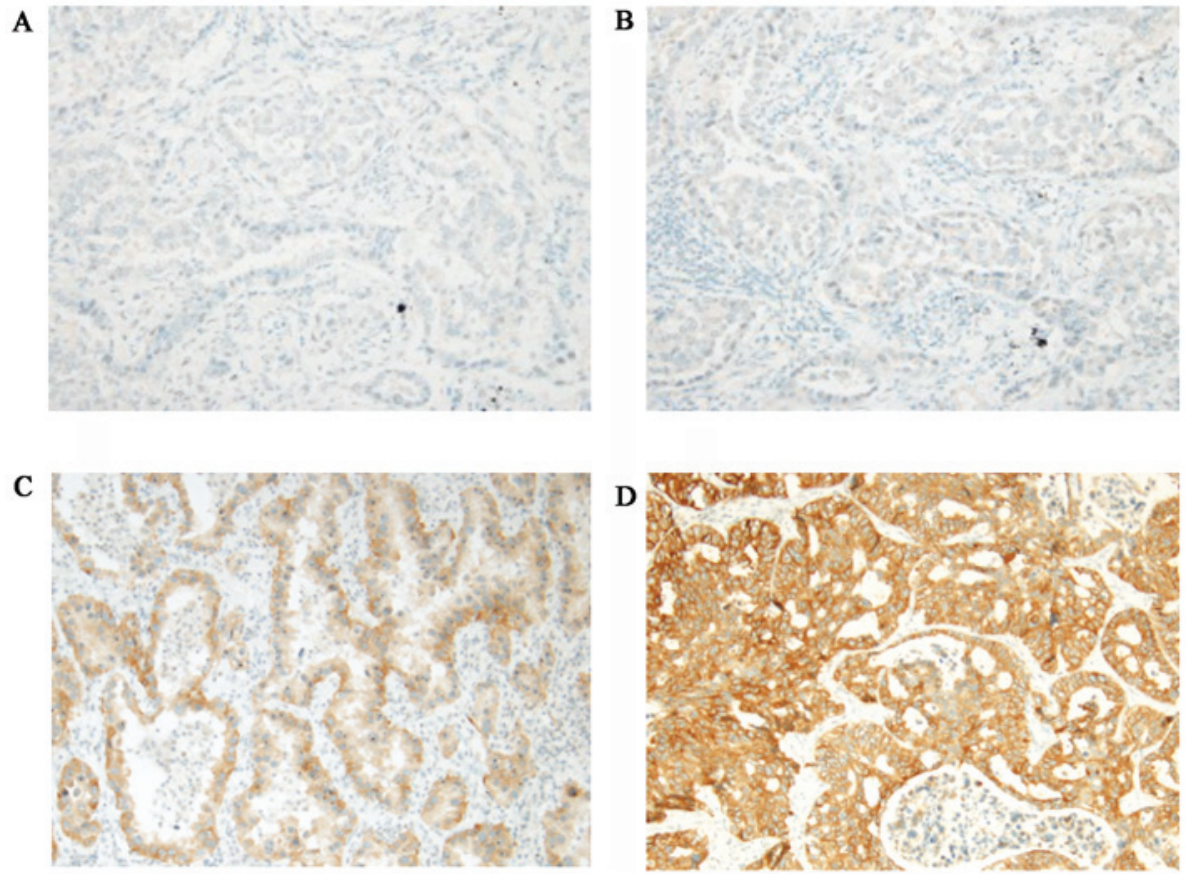

Figure 1. Representative IHC fields using SP111. (A) No significant staining (score 0). (B) Light-yellow staining with no obvious particulates or yellow staining with obvious particulates in $<10 \%$ of tumor cells (score 1+). (C) Yellow staining with obvious particulates in $>10 \%$ of tumor cells or brown staining with obvious particulates in $<10 \%$ of tumor cells. (D) Brown staining with obvious particulates in $>10 \%$ of tumor cells. Magnification, $x 200$.

Therefore, the sensitivity and specificity of both SP111 and SP125 were $100 \%$ (Table II).

The seven cases without EGFR mutations were negative by ICC using SP111 and SP125. Among the three cases with
delE746-A750, one was positive by ICC using SP111. Thus, the sensitivity and specificity of SP111 were 33.3 and $100 \%$, respectively. Five of seven cases with the L858R mutation showed positive staining for SP125; thus, the sensitivity 
Table II. Summary of IHC and molecular testing in resection samples.

\begin{tabular}{lccc}
\hline IHC & Exon19del $(\mathrm{n}=3)(\%)$ & L858R $(\mathrm{n}=7)(\%)$ & No mutation $(\mathrm{n}=7)(\%)$ \\
\hline SP111-positive & $3(100)$ & $0(0)$ & $0(0)$ \\
SP111-negative & $0(0)$ & $7(100)$ & $7(100)$ \\
SP125-positive & $0(0)$ & $7(100)$ & $0(0)$ \\
SP125-negative & $3(100)$ & $0(0)$ & $7(100)$ \\
\hline
\end{tabular}

IHC, immunohistochemistry.

A

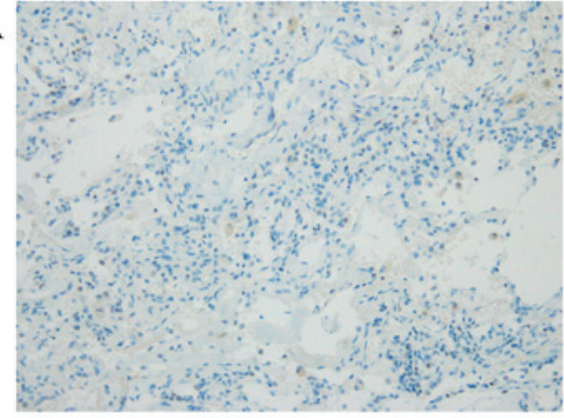

$\mathrm{C}$

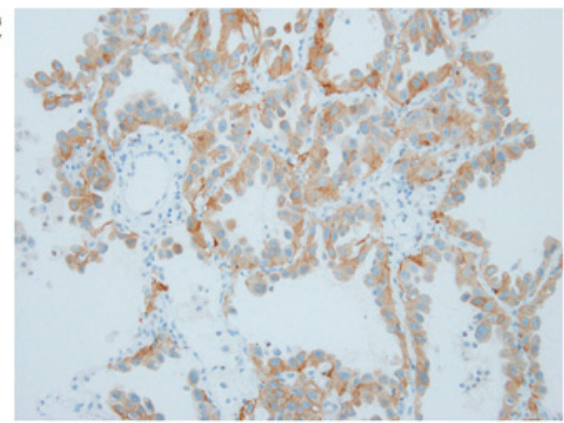

$\mathrm{B}$
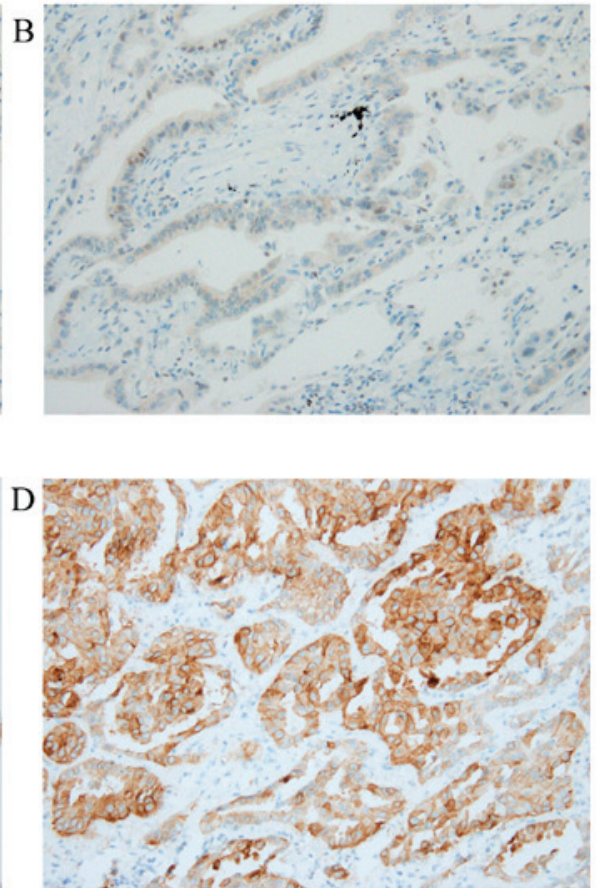

Figure 2. Representative IHC fields using SP125. (A) No significant staining (score 0). (B) Light-yellow staining with no obvious particulates or yellow staining with obvious particulates in $<10 \%$ of tumor cells (score 1+). (C) Yellow staining with obvious particulates in $>10 \%$ of tumor cells or brown staining with obvious particulates in $<10 \%$ of tumor cells. (D) Brown staining with obvious particulates in $>10 \%$ of tumor cells. Magnification, x200.

A

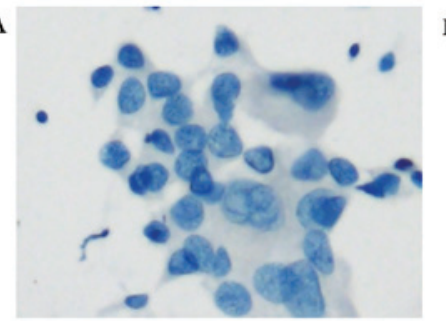

B

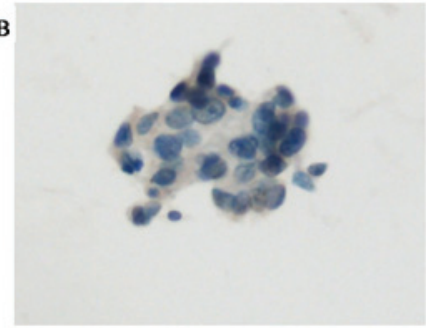

c



Figure 3. Representative ICC fields using SP111. Similar to IHC, a four-grade scoring system (0 to 3+) was employed. Scores of (A) 0 , (B) 1+, and (C) 2+. Magnification, x200.

and specificity of SP125 were 71.4 and $100 \%$, respectively (Table III).

Comparative analyses between IHC and ICC. ICC scores of $2+$ and $3+$ were considered positive. However, other studies used diverse cut-off values; e.g., Tsai et al regarded a score of $1+, 2+$, or $3+$ as positive $(25)$. We analyzed the concordance of molecular testing and ICC using various cut-off values by calculating the PPV, NPV, and Cohen's kappa score. If a score of $\geq 1+$ was considered positive, the sensitivity, specificity, PPV, $\mathrm{NPV}$, and the $\kappa$ values were $100,57.1,76.9,100 \%$, and 0.611 , respectively for IHC and 100, 55.6, 66.7, 100\%, and 0.239, respectively, for ICC (Table IV).

If a score of $\geq 2+$ was considered positive, the sensitivity, specificity, PPV, NPV, and the $\kappa$ values were $100,100,100$, $100 \%$, and 1.0, respectively, for IHC and 60.0, 100, 100, 63.6\%, 
Table III. Summary of ICC and molecular testing in resection samples.

\begin{tabular}{lccc}
\hline ICC & Exon19del $(\mathrm{n}=3)(\%)$ & L858R $(\mathrm{n}=7)(\%)$ & No mutation $(\mathrm{n}=7)(\%)$ \\
\hline SP111-positive & $1(33.3)$ & $0(0)$ & $0(0)$ \\
SP111-negative & $2(66.7)$ & $7(100)$ & $7(100)$ \\
SP125-positive & $0(0)$ & $5(71.4)$ & $0(0)$ \\
SP125-negative & $3(100)$ & $2(28.6)$ & $7(100)$
\end{tabular}

ICC, immunocytochemistry.

Table IV. Comparative analyses between IHC and ICC in accordance with grading.

\begin{tabular}{lcccccc}
\hline $\begin{array}{l}\text { Consideration regarding } \\
\text { positive result }\end{array}$ & Type & Sensitivity, \% & Specificity, \% & PPV, \% & NPV, \% & Cohen's Kappa Score \\
\hline Score $\geq 1$ & IHC & 100 & 57.1 & 76.9 & 100 & 0.611 \\
& ICC & 100 & 55.6 & 66.7 & 100 & 1 \\
Score $\geq 2$ & IHC & 100 & 100 & 100 & 100 & 0.239 \\
& ICC & 60.0 & 100 & 100 & 63.6 & 0.553 \\
Score $\geq 3$ & IHC & 50.0 & 100 & 100 & 58.3 & 50.0 \\
& ICC & 30.0 & 100 & 100 & 50.45 & 0.261 \\
\hline
\end{tabular}

IHC, immunohistochemistry; ICC, immunocytochemistry; PPV, positive predictive value; NPV, negative predictive value.
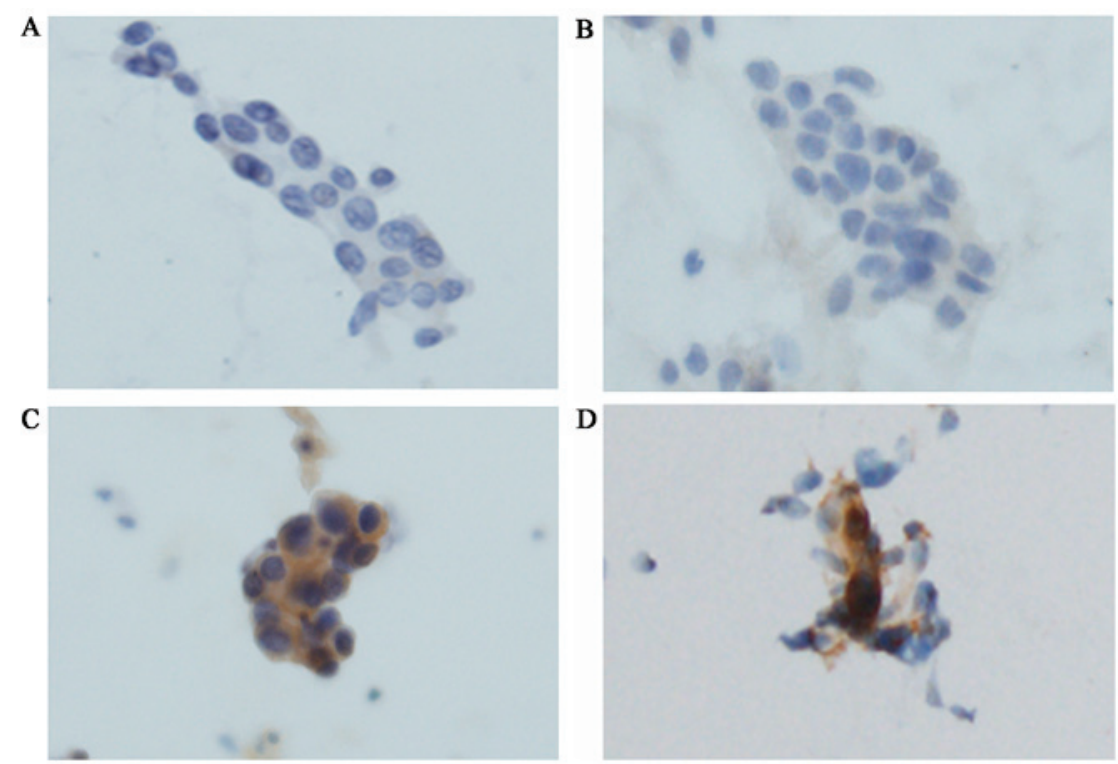

Figure 4. Representative ICC fields using SP125. Similar to IHC, a four-grade score was employed. Scores of (A) 0, (B) 1+, (C) 2+, and (D) 3+. Magnification, x200.

and 0.553 , respectively, for ICC (Table IV). If a score of $\geq 3+$ was considered positive, the abovementioned values were 50.0, $100,100,58.3 \%$, and 0.452 , respectively, for IHC and 30.0 , $100,100,50.0 \%$, and 0.261 , respectively, for ICC.

\section{Discussion}

Greater understanding of the molecular pathogenesis of lung cancer has led to the development and application of targeted therapeutic strategies. Activating somatic mutations in EGFR are associated with a clinical response to TKIs (3-5). Thus, molecular testing of EGFR mutations has become routine in clinical practice $(9,10)$. However, such tests are expensive and technically difficult to perform in many laboratories. IHC is an inexpensive and accurate method of identifying EGFR mutations and is available in most pathology laboratories. Several authors evaluated the potential of antibodies specific for the delE746-A750 and L858R mutations for screening for EGFR 
mutations using surgically resected and biopsy samples (11-21). Compared with biopsy samples, obtaining cytological specimens is minimally invasive and simple. Several studies evaluated ICC using EGFR mutation-specific antibodies (clone 43B2 and clone 6B6) in cytological specimens (18,24-26). Two novel antibodies specific for EGFR mutations were developed recently: SP111, which is specific for delE746-A750, and SP125, which is specific for the L858R mutation. To date, no report has evaluated the use of SP111 or SP125 with cytological specimens. Thus, we evaluated the potential of these novel EGFR mutation-specific antibodies in ICC.

The present study included 17 cases with surgically resected and cytological samples available. Seven cases were positive for the L858R mutation and three cases for delE746-A750; the remaining seven cases had neither mutation. In ICC, the sensitivity and specificity of SP111 were 33.3 and $100 \%$, respectively. In ICC, the sensitivity and specificity of clone 6B6 for delE746-A750 samples were reportedly 66.7 and $83.3 \%, 100$ and $94 \%, 88$ and $96 \%$, and 72.7 and $100 \%$, respectively $(18,24-26)$. The sensitivity of SP111 was inferior to that of clone $6 \mathrm{~B} 6$, but its specificity was comparable or superior. The sensitivity and specificity of SP125 were 71.4 and $100 \%$, respectively. Previous studies reported sensitivities and specificities for clone 43B2 of 42.9 and 50\%, 100 and $100 \%, 71$ and $86 \%$, and 80 and $93.8 \%$, respectively (18,24-26). Thus, the sensitivity of SP125 is comparable with that of clone $43 \mathrm{~B} 2$, but its specificity is comparable with or superior to that of clone 43B2.

The sensitivity and specificity of SP111 in ICC were 33.3 and $100 \%$, respectively, and those of SP125 were 71.4 and $100 \%$, respectively; therefore, the combined sensitivity and specificity were 60 and $100 \%$, respectively (Table IV). The combined sensitivity of clones 43B2 and 6B6 in IHC is reportedly higher than that in ICC (79.7 vs. $50 \%$ and 85.2 vs. $66.7 \%$, respectively) $(18,26)$. These findings suggest that ICC using antibodies to the L858R and delE746-A750 mutations exhibits low sensitivity. Tumor cells tend to form clusters, which hampers the evaluation of membrane-positive signals. This issue may be resolved by disrupting the tumor cell clusters.

The meta-analysis by Chen et al recommended a four-grade IHC scoring system (in which a score of $2+$ or $3+$ is considered positive), not only to reduce differences among readers, but also to enhance the diagnostic value of mutation-specific antibodies (21). In this study, the PPV, NPV, and Cohens' kappa value were highest when a score of $\geq 2+$ was considered positive. Therefore, a cut-off score of 2+ may be suitable for both IHC and ICC.

Based on the high specificity of ICC using SP111 and SP125, a positive result may eliminate the need for confirmatory molecular testing. Patients with positive cytological samples should immediately start TKI therapy without verification by molecular testing. Screening for EGFR mutations by ICC may facilitate therapeutic decision-making, particularly in medical centers unable to perform molecular testing.

\section{Acknowledgements}

The present study was supported by grants from the Ministry of Education, Culture, Sports, Science and Technology, Japan (T17K195550).

\section{References}

1. Fact Sheet WHO: 297.www.who.org a.WHO Fact Sheet 297. Accessed on November 8, 2016.

2. Travis WD, Rekhtman N, Riley GJ, Geisinger KR, Asamura H, Brambilla E, Garg K, Hirsch FR, Noguchi M, Powell CA, et al: Pathologic diagnosis of advanced lung cancer based on small biopsies and cytology: A paradigm shift. J Thorac Oncol 5: 411-414, 2010.

3. Lynch TJ, Bell DW, Sordella R, Gurubhagavatula S, Okimoto RA, Brannigan BW, Harris PL, Haserlat SM, Supko JG, Haluska FG, et al: Activating mutations in the epidermal growth factor receptor underlying responsiveness of non-small-cell lung cancer to gefitinib. N Engl J Med 350: 2129-2139, 2004.

4. Paez JG, Jänne PA, Lee JC, Tracy S, Greulich H, Gabriel S, Herman P, Kaye FJ, Lindeman N, Boggon TJ, et al: EGFR mutations in lung cancer: Correlation with clinical response to gefitinib therapy. Science 304: 1497-1500, 2004.

5. Pao W, Miller V, Zakowski M, Doherty J, Politi K, Sarkaria I, Singh B, Heelan R, Rusch V, Fulton L, et al: EGF receptor gene mutations are common in lung cancers from 'never smokers' and are associated with sensitivity of tumors to gefitinib and erlotinib. Proc Natl Acad Sci USA 101: 13306-13311, 2004.

6. Sharma SV, Bell DW, Settleman J and Haber DA: Epidermal growth factor receptor mutations in lung cancer. Nat Rev Cancer 7: 169-181, 2007.

7. Mitsudomi T and Yatabe Y: Mutations of the epidermal growth factor receptor gene and related genes as determinants of epidermal growth factor receptor tyrosine kinase inhibitors sensitivity in lung cancer. Cancer Sci 98: 1817-1824, 2007.

8. Mok TS, Wu YL, Thongprasert S, Yang CH, Chu DT, Saijo N, Sunpaweravong P, Han B, Margono B, Ichinose Y, et al: Gefitinib or carboplatin-paclitaxel in pulmonary adenocarcinoma. N Engl J Med 361: 947-957, 2009.

9. Pao W and Ladanyi M: Epidermal growth factor receptor mutation testing in lung cancer: Searching for the ideal method. Clin Cancer Res 13: 4954-4955, 2007.

10. Ellison G, Zhu G, Moulis A, Dearden S, Speake G and McCormack R: EGFR mutation testing in lung cancer: A review of available methods and their use for analysis of tumour tissue and cytology samples. J Clin Pathol 66: 79-89, 2013.

11. Yu J, Kane S, Wu J, Benedettini E, Li D, Reeves C, Innocenti G, Wetzel R, Crosby K, Becker A, et al: Mutation-specific antibodies for the detection of EGFR mutations in non-small-cell lung cancer. Clin Cancer Res 15: 3023-3028, 2009.

12. Brevet M, Arcila M and Ladanyi M: Assessment of EGFR mutation status in lung adenocarcinoma by immunohistochemistry using antibodies specific to the two major forms of mutant EGFR. J Mol Diagn 12: 169-176, 2010.

13. Kato Y, Peled N, Wynes MW, Yoshida K, Pardo M, Mascaux C, Ohira T, Tsuboi M, Matsubayashi J, Nagao T, et al: Novel epidermal growth factor receptor mutation-specific antibodies for non-small cell lung cancer: Immunohistochemistry as a possible screening method for epidermal growth factor receptor mutations. J Thorac Oncol 5: 1551-1558, 2010.

14. Kawahara A, Yamamoto C, Nakashima K, Azuma K, Hattori S, Kashihara M, Aizawa H, Basaki Y, Kuwano M, Kage M, et al: Molecular diagnosis of activating EGFR mutations in non-small cell lung cancer using mutation-specific antibodies for immunohistochemical analysis. Clin Cancer Res 16: 3163-3170, 2010.

15. Kitamura A, Hosoda W, Sasaki E, Mitsudomi T and Yatabe Y: Immunohistochemical detection of EGFR mutation using mutation-specific antibodies in lung cancer. Clin Cancer Res 16: 3349-3355, 2010.

16. Nakamura H, Mochizuki A, Shinmyo T, Ando K, Kurimoto N, Yokote $\mathrm{K}$ and Takagi M: Immunohistochemical detection of mutated epidermal growth factor receptors in pulmonary adenocarcinoma. Anticancer Res 30: 5233-5237, 2010.

17. Kozu Y, Tsuta K, Kohno T, Sekine I, Yoshida A, Watanabe S, Tamura T, Yokota J, Suzuki K, Asamura H, et al: The usefulness of mutation-specific antibodies in detecting epidermal growth factor receptor mutations and in predicting response to tyrosine kinase inhibitor therapy in lung adenocarcinoma. Lung Cancer 73: 45-50, 2011.

18. Jiang G, Fan C, Zhang X, Dong Q, Wang L, Liu Y, Dai S, Yang L, Zhang Y, Yu J and Wang E: Ascertaining an appropriate diagnostic algorithm using EGFR mutation-specific antibodies to detect EGFR status in non-small-cell lung cancer. PLoS One 8: e59183, 2013 
19. Simonetti S, Molina MA, Queralt C, de Aguirre I, Mayo C, Bertran-Alamillo J, Sanchez JJ, Gonzalez-Larriba JL, Jimenez U, Isla $\mathrm{D}$, et al: Detection of EGFR mutations with mutation-specific antibodies in stage IV non-small-cell lung cancer. J Transl Med 8: 135, 2010.

20. Xiong Y, Bai Y, Leong N, Laughlin TS, Rothberg PG, Xu H, Nong L, Zhao J, Dong Y and Li T: Immunohistochemical detection of mutations in the epidermal growth factor receptor gene in lung adenocarcinomas using mutation-specific antibodies. Diagn Pathol 8: 27, 2013.

21. Chen Z, Liu HB, Yu CH, Wang Y, Wang L and Song Y: Diagnostic value of mutation-specific antibodies for immunohistochemical detection of epidermal growth factor receptor mutations in non-small cell lung cancer: A meta-analysis. PLoS One 9: e105940, 2014

22. Wang T, Nelson RA, Bogardus A and Grannis FW Jr: Five-year lung cancer survival: Which advanced stage nonsmall cell lung cancer patients attain long-term survival? Cancer 116: 1518-1525, 2010.

23. Molina JR, Adjei AA and Jett JR: Advances in chemotherapy of non-small cell lung cancer. Chest 130: 1211-1219, 2006.

24. Kawahara A, Azuma K, Sumi A, Taira T, Nakashima K Aikawa E, Abe H, Yamaguchi T, Takamori S, Akiba J and Kage M: Identification of non-small-cell lung cancer with activating EGFR mutations in malignant effusion and cerebrospinal fluid: Rapid and sensitive detection of exon 19 deletion E746-A750 and exon 21 L858R mutation by immunocytochemistry. Lung Cancer 74: 35-40, 2011
25. Tsai TH, Wu SG, Chang YL, Wu CT, Tsai MF, Wei PF, Yang CH, Yu CJ, Yang PC and Shih JY: Effusion immunocytochemistry as an alternative approach for the selection of first-line targeted therapy in advanced lung adenocarcinoma. J Thorac Oncol 7: 993-1000, 2012.

26. Kawahara A, Taira T, Azuma K, Tominaga M, Hattori S, Kawahara M, Abe H, Yamaguchi T, Akiba J, Takamori S, et al: A diagnostic algorithm using EGFR mutation-specific antibodies for rapid response EGFR-TKI treatment in patients with non-small cell lung cancer. Lung Cancer 78: 39-44, 2012.

27. Allo G, Bandarchi B, Yanagawa N, Wang A, Shih W, Xu J, Dalby M, Nitta H, To C, Liu N, et al: Epidermal growth factor receptor mutation-specific immunohistochemical antibodies in lung adenocarcinoma. Histopathology 64: 826-839, 2014.

28. Seo AN, Park TI, Jin Y, Sun PL, Kim H, Chang H and Chung JH: Novel EGFR mutation-specific antibodies for lung adenocarcinoma: Highly specific but not sensitive detection of an E746_A750 deletion in exon 19 and an L858R mutation in exon 21 by immunohistochemistry. Lung Cancer 83: 316-323, 2014.

29. Kim CH, Kim SH, Park SY, Yoo J, Kim SK and Kim HK: Identification of EGFR mutations by immunohistochemistry with EGFR mutation-specific antibodies in biopsy and resection specimens from pulmonary adenocarcinoma. Cancer Res Treat 47: 653-660, 2015. 